\title{
Analysis of Plasma Cortisol Level and Salivary Cortisol Level in Chronic Kidney Disease Patients with Depression
}

\author{
Arina Widya Murni ${ }^{1}$, Ellyza Nasrul ${ }^{2}$, Fadrian $^{3}$ \\ \{arina_widya_murni@yahoo.com, arinawidyamurni@med.unand.ac.id ${ }^{1}$ \} \\ Departement of Internal Medicine Sub division Psychosomatic Medicine ${ }^{1}$ \\ Department of Clinical Pathology 2 \\ Department of Internal Medicine Sub Division of Tropical Infection, Faculty of Medicine Universitas \\ Andalas, M. Djamil Hospital, Padang, Indonesia ${ }^{3}$
}

\begin{abstract}
Chronic Kidney Disease (CKD) had increasing mortality rate every year caused by various causes such as depression. Depression also affects the length of stay, nutritional status and adherence to taking drugs and undergoing hemodialysis. Depression more objectively diagnosing by looking at the value of plasma cortisol levels. Salivary cortisol hormone examination is better because it was non-invasive and more reliable. The aim of this study was to analyze the relationship between plasma cortisol levels and salivary cortisol in chronic kidney disease patients with depression. A cross sectional study, with consecutive sampling was done. There are 50 patient get a blood and saliva sampling, and screening depression with Beck Depression Inventory. Cortisol hormone was check in morning and evening. The data was perform for correlation between cortisol level and stress in two condition morning or evening. The results of this study, there were 50 patients, the mean age of $53.62 \pm 13.46$ years. The mean level of urea was $172.44 \pm 95.47 \mathrm{mg} / \mathrm{dL}$. Mean of creatinine was $9.83 \pm 7.06 \mathrm{mg} / \mathrm{dL}$. The mean of morning plasma cortisol level was 62.77 $\pm 15.81 \mu \mathrm{g} / \mathrm{dL}$ and the mean of afternoon blood cortisol level was $59.82 \pm 12.44 \mu \mathrm{g} / \mathrm{dL}$. The mean of salivary cortisol level is $0.72 \pm 1.45 \mu \mathrm{g} / \mathrm{dL}$. There was a significant correlation between morning plasma cortisol levels with salivary cortisol levels $(\mathrm{p}=0.007)$ in patients with chronic kidney disease with depression.
\end{abstract}

Keywords : Cortisol plasma, Depression, Salivary Cortisol.

\section{Introduction}

Chronic Kidney Disease (CKD) is a chronic disease that is a major health problem in the world and in Indonesia. The prevalence of CKD in the developing world ranges from $15 \%$ and reaches $8-16 \%$ in the world. Ranking of CKD as a cause of death in the world raised from 27 th in 1999 to 18th in 2010 and is expected to increase every year [1].

Chronic Kidney Disease (CKD) is a disease characterized by a decrease in kidney function that progresses chronic progressively, at least in three months there is a decrease in glomerolus filtration rate of less than $60 \mathrm{ml} / \mathrm{min}$ per $1.73 \mathrm{~m} 2$ of body surface area. At a glomerulous filtration rate of less than $15 \mathrm{ml} /$ minute, patients with CKD require dialysis to maintain their lives. [2] CKD patients have the potential to experience psychological problems. Depression is a psychological problem that is often found in CKD, especially those undergoing hemodialysis. Chronic illnesses, various diagnostic and definitive treatments with hemodialysis are some of the stressors that trigger psychological problems in people with CKD. 
Research by Andrade and Sesso (2012) regarding depression in CKD patients undergoing hemodialysis found that BDI scores were higher in hemodialysis patients compared to conservative therapy (41.6\% vs $37.3 \%)$ [3].

Depression affects the risk of death, there is an increase in mortality in CKD who are depressed compared to other chronic cases. Depression also increases hospital stay, also affects nutrition and levels of medication adherence, both pharmacological and non-pharmacological [4] [5].

Research in 2012 in the department of internal medicine Dr. M Djamil Padang about the duration of hemodialysis action and its relationship with depression found a significant relationship between the duration of hemodialysis with depression, the longer undergoing hemodialysis, the higher the risk of depression. From this study also found that about $46 \%$ of patients did not experience depression and $64 \%$ experienced depression with mild depression $38 \%$, moderate $18 \%$ and weight $2 \%$ [6].

Uremia itself affects hormone dysregulation in CKD patients where there is an exogenous release of a hormone called ovine Cortico Releasing Hormone (oCRH) which results in dysregulation of the HPA Axis. In the final stage of CKD, the HPA Axis function can be confused. Marked by an increase in morning cortisol levels circulating in the circulation and night cortisol levels also increase due to increased of ACTH secretion.

There is a difference in plasma cortisol with salivary cortisol in patients with CKD, which is influenced by the level of protein in the blood, as a binding hormone. Examination of the hormone cortisol through serum samples illustrates the total value of hormones in the blood, while the examination using saliva better describes levels of hormones that are free or unbound or more accurately describe the fraction of the hormone cortisol itself [7].

Depression can aggravate CKD patients in terms of non-compliance, affect nutritional status and lead to death. But depression in CKD is difficult to ascertain by just seeing the clinical course of depression. Depressive symptoms can be found to overlap with their own uremic symptoms. Overlapping symptoms of uremia with depressive symptoms in CKD patients can be ascertained by looking at the cortisol levels of the sufferer. Considering that cortisol in the circulation is affected by blood proteins that experience CKD disturbances, it is necessary to study the differences in plasma cortisol with salivary cortisol to obtain objective cortisol levels in strengthening clinical depression in CKD. The Aims of this study are to assess the relationship between plasma cortisol levels and cortisol saliva levels in Chronic Kidney Disease Patients with Depression

\section{Methods}

The type of this research is comparative analytic observational with cross sectional study design and the dependent and independent variables are examined at the same time. The study was conducted in the ward of Internal Medicine Dr. M. Djamil Padang for 6 month. The population of this study are chronic kidney disease patients who experienced depression who were treated in the ward of Internal Medicine Dr. M. Djamil Padang. The research sample is a population that meets the inclusion are no history of previous mental disorder and willing to participate in the research and sign the approval sheet. The exclusion criteria is patients with decreased of consciousness 


\subsection{Procedure}

1. Patients with chronic kidney disease, if they are willing to take part in this research and do not meet the exclusion criteria are asked for approval and willingness to participate in this study.

2. Record the name, age, sex and comorbidities of the patient.

3. Determined BDI scores using the BDI questionnaire, by filling out a questionnaire by the examiner with interview techniques.

4. Checked plasma cortisol of the patient

\subsection{Blood Cortisol}

Cortisol levels in the blood following the diurnal cycle. In the morning, serum levels of cortisol are twice higher than the level of the afternoon. Samples are taken from the patient's serum and examined by the Elecysys Cortisol Reagent Kit reagent and using the electrochemiluminescence immunoassay (ECLIA) examination system on the Roche Elecsys 1010/2010 and modular analitycs E 170.

Sample Requirements:

Volume 300 - 500 uL, Serum Sample

Container tube clot activator, tube SST (clot activator + gel)

For the morning specimen between $06.00-08.00$, and the highest level of Cortisol is achieved at $06.00-08.00 \mathrm{am}$ and decreased to the lowest level in the middle night)

For specimens in the afternoon between 3:00 a.m. and 5:00 p.m.

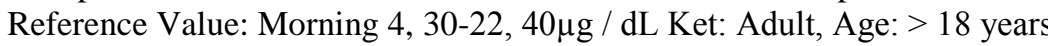

\section{a. Salivary Cortisol}

Patients were also examined for salivary cortisol. Saliva sampling is carried out together with blood sampling. Saliva is collected in polypropylene vials using the help of special tools. Saliva samples are collected and frozen to be examined in the same day. Salivary cortisol examination using immunoassay kit (EIA)

\section{b. Research Ethics}

This study was approved by Research Ethics Committee of Medical Faculty, Andalas University. (No 438/KEP/FK / 2017)

\section{c. Statistical Analysis}

Descriptive statistical analysis of the basic data which includes patient characteristics, numerical data is displayed in the form of averages and standard deviations. In numerical data, normality tests were conducted using the Kolmogorov Smirnov test. Analysis of the relationship between plasma cortisol values and salivary cortisol values was analyzed. Correlation analysis used is Pearson correlation test and confidence level <0.05. Data processed with SPSS, calculated the significance value, meaningful if $\mathrm{p}<0.05$.

\section{Results}

In this study obtained 25 men $(50 \%)$ and 25 women $(50 \%)$ with a mean age of the study sample was $53.62 \pm 13.46$ years. The largest age group is aged $16-85$ years. The mean urea in the study sample was $172.44 \pm 95.47 \mathrm{mg} / \mathrm{dl}$. The mean creatinine in the study sample was 9.83 
$\pm 7.06 \mathrm{mg} / \mathrm{dl}$. The mean of morning blood cortisol was $62.77 \pm 15.81$ and the mean of afternoon blood cortisol was $59.82 \pm 12.44$. The mean salivary cortisol in this patient was $0.72 \pm 1.45$. For more details can be seen in table 5.1 as below.

Table 1. Basic Characteristics of Research Sample

Variable $\mathrm{n}(\%) \quad$ Mean (SD)

$\begin{array}{ll}\text { Sex } & \\ \text { Male } & 25(50) \\ \text { Female } & 25(50)\end{array}$

Age (years)

$53,62 \pm 13,46$

$\operatorname{Ureum}(\mathrm{mg} / \mathrm{dL})$

$172,44 \pm 95,47$

Creatinine $(\mathrm{mg} / \mathrm{dL})$

$9,83 \pm 7,05$

Morning Plasma Cortisol Levels in Chronic Kidney Disease Patients with Depression.

In this study obtained mean morning plasma cortisol levels in depressive ESRD patients 62.77

$\pm 15.81 \mathrm{mg} / \mathrm{dl}$ with the lowest levels is $36.53 \mathrm{mg} / \mathrm{dL}$ and the highest levels is $110.63 \mathrm{mg} / \mathrm{dl}$.

Table 2. Morning Plasma Cortisol Levels in Chronic Kidney Disease Patients with

Depression

\begin{tabular}{ccc}
\hline Variable & Mean $(\mathrm{ng} / \mathrm{mL})$ & SD $(\mathrm{mg} / \mathrm{dL})$ \\
\hline Morning plasma cortisol level & 62.77 & \pm 15.81 \\
\hline
\end{tabular}

Afternoon Plasma Cortisol Levels in Chronic Kidney Disease Patients with Depression In this study, the mean of plasma cortisol level was obtained in CKD patients with depression $59.82 \pm 12.44 \mathrm{mg} / \mathrm{dl}$ with the lowest level of $31.48 \mathrm{mg} / \mathrm{dL}$ and the highest level of $93.17 \mathrm{mg}$ / dL.

Table 3. Afternoon Plasma Cortisol Levels in Chronic Kidney Disease Patients with Depression.

\begin{tabular}{ccc}
\hline Variable & Mean $(\mathrm{ng} / \mathrm{mL})$ & SD $(\mathrm{ng} / \mathrm{mL})$ \\
\hline Afternoon Plasma Cortisol Levels & 59.82 & \pm 12.44 \\
\hline
\end{tabular}

Salivary Cortisol Levels in Chronic Kidney Disease Patients with Depression.

In this study obtained the mean of salivary cortisol levels in CKD patients with depression is $0.73 \pm 1.45 \mathrm{mg} / \mathrm{dl}$ with the lowest level is $0.12 \mathrm{mg} / \mathrm{dL}$ and the highest level is $8.60 \mathrm{mg} / \mathrm{dl}$.

Table 4. Salivary Cortisol Levels in Chronic Kidney Disease Patients with Depression

\begin{tabular}{ccc}
\hline Variable & Mean $(\mathrm{ng} / \mathrm{mL})$ & SD $(\mathrm{mg} / \mathrm{dL})$ \\
\hline Salivary Cortisol Levels & 0,72 & $\pm 1,45$ \\
\hline
\end{tabular}


Table 5. Correlation between Plasma Cortisol Levels with Salivary Cortisol Levels in Chronic Kidney Disease Patients with Depression

\begin{tabular}{ccc}
\hline Variable & $\begin{array}{c}\text { Salivary Cortisol Levels } \\
(\mathrm{mg} / \mathrm{dL})\end{array}$ & \\
\hline $\begin{array}{c}\text { Morning plasma cortisol level (mg/dL) } \\
62.77 \pm 15.81\end{array}$ & $0,73 \pm 1,45$ & $\mathbf{p}=\mathbf{0 , 0}$ \\
\hline $\begin{array}{c}\text { Afternoon plasma cortisol level (mg/dL) } \\
59.82 \pm 12.44\end{array}$ & $0,73 \pm 1,45$ & $\mathbf{p}=\mathbf{0 , 9 5 8}$ \\
\hline
\end{tabular}

Table 5. show the correlation between morning plasma cortisol levels with salivary cortisol levels in CKD patients with depression. The results of the analysis showed a significant correlation between morning plasma cortisol levels and salivary cortisol with $\mathrm{p}=0.007$. Meanwhile, afternoon plasma cortisol did not show a significant relationship with salivary cortisol with $\mathrm{p}=0.958$.

\section{Discussion}

We had been done research on 50 patients with Chronic Kidney Disease in Internal Medicine and Hemodialysis Unit of Dr. M. Djamil Hospital in Padang. The sample was collected from August 2017 until October 2017. The study was conducted to determine the mean of blood cortisol levels in the morning, to find out the mean blood cortisol levels in the afternoon, and to determine the mean levels of salivary cortisol in CKD patients with depression and to know the correlation of blood cortisol levels with cortisol saliva in patients with CKD patients with depression.

The sample of the study was selected from CKD patients with depression (BDI> 11). The sample of this study met the inclusion criteria. CKD patients with decreased of consciousness were not included in this study.

\subsection{Characteristics of Sample of the study}

This study obtained 25 men $(50 \%)$ and 25 women $(50 \%)$ with a mean age of the study sample was $53.62 \pm 13.46$ years. The mean ureum of subject in the study was $172.44 \pm 95.47$ $\mathrm{mg} / \mathrm{dl}$. The mean creatinine of subject in the study was $9.83 \pm 7.06 \mathrm{mg} / \mathrm{dl}$. The mean of morning blood cortisol was $62.77 \pm 15.81$ and the mean of afternoon blood cortisol was 59.82 \pm 12.44 . The mean salivary cortisol in this patient was $0.72 \pm 1.45$.

The mean ureum of patients in this study was $172.44 \pm 95.47(\mathrm{mg} / \mathrm{dL})$. Haleni et al, 2012 reported the mean urea of PGTA patients was $160.2 \pm 90.24(\mathrm{mg} / \mathrm{dL})$. Whereas Workmanet et al reported the mean creatinine of CKD patients was 9.03 (6.5) years. The mean ureum in Halen et al's 2012 study was similar when compared with this study. Whereas creatinine mean in the Workmanet et al study also similar to creatinine mean in this study. This can be explained that in the study there were no differences in sample urea and creatinine that participated in the study with previous studies [8] 


\subsection{Morning and Afternoon Blood Cortisol Levels in Patients with Chronic Kidney Disease with Depression.}

This study obtained the mean afternoon blood cortisol levels $59.82 \pm 12.44 \mathrm{mg} / \mathrm{dl}$ with the lowest levels of $31.48 \mathrm{mg} / \mathrm{dl}$ and the highest level of $93.17 \mathrm{mg} / \mathrm{dl}$. Mean morning blood cortisol levels obtained $62.77 \pm 15.81 \mathrm{mg} / \mathrm{dl}$ with the lowest levels of $36.53 \mathrm{mg} / \mathrm{dl}$ and the highest level of $110.63 \mathrm{mg} / \mathrm{dl}$.

The results of this study are lower than some previous studies. Jorge et al. Who reported afternoon blood cortisol levels of $61.53 \pm 12.4) \mathrm{ng} / \mathrm{mL}$. Carrillo-Vega et al reported the mean afternoon blood cortisol levels in Mexico at $63.53 \pm 12.56 \mathrm{ng} / \mathrm{mL}$. Enstrud et al reported the mean afternoon blood cortisol levels in the United States of $63.66 \pm 12.62 \mathrm{ng} / \mathrm{mL}$.

\subsection{Correlation of Blood Cortisol Levels with Saliva Cortisol}

Based on the correlation test, there was a correlation between morning blood cortisol and salivary cortisol and was statistically significant. The correlation between afternoon blood cortisol and salivary cortisol showed insignificant results.

Workmanet et al (2016) investigated cortisol values of saliva, blood and urine with chronic kidney disease without depression. Salivary cortisol shows a negative correlation with glomerular filtration rate or is not affected by uremia. In the study it was found that blood cortisol value was strongly influenced by glomerular filtration rate. Blood cortisol circulating in the blood requires protein for distribution in the blood called Cortisol Binding Globulin. [8]

Pabst et al (2014) also found that, regardless of the accompanying depressive status, salivary cortisol results were not affected by the value of uremia. Blood cortisol is less reliable because its value is fluctuate [8]

Salivary cortisol has been widely used as a marker of dysregulation of hypothalamus Axis Pituitary Adrenal (HPA) and aging process. High salivary cortisol levels reflect the dysregulation process of Axic Hypothalamic Pituitary Adrenal (HPA) due to increased of cortisol synthesis. Cortisol is one of the final products of cortisol synthesis through the hypothalamic-pituitary-adrenal axis [9]

In this study, the mean salivary cortisol levels were $0.72 \pm 1.45 . \mu \mathrm{g} / \mathrm{dL}$. Salivary cortisol levels in this study were higher than normal values $(0.007-0.115 \mu \mathrm{g} / \mathrm{dL})$. This is due to depression in PGTA associated with dysregulation of the Hipothalamus Pituitary Adrenal (HPA) Axis. The Axothalamus Pituitary Adrenal (HPA) Axis is a neuroendocrine system that regulates the production and secretion of glucocorticoid hormones. The hypothalamus secretes Corticotropin Releasing Hormone $(\mathrm{CRH})$ which stimulates the pituitary gland to secrete Adrenocorticotropic Releasing Hormone (ACTH) which stimulates the adrenals to secrete cortisol hormone in the tissues. In CKD conditions that do not affect uremia are salivary cortisol [10]

This study concludes that salivary cortisol values are significantly associated with morning cortisol in CKD patients with depression, meaning that salivary cortisol examination can be used to detect depression in CKD patients to get definitive evidence of depression. 


\section{Conclusion}

There is significant relation between morning cortisol plasma with salivary cortisol in patient chronic kidney disease with depression.

\section{References}

[1]Chilcot J, Davenport A, Wellsted D, Firth J, Farrington K. An association between depressive symptoms and survival in incident dialysis patients. Nephrol, Dial. Transplant 26 pp 1628-34 (2011)

[2]Baines LS, Joseph JT and Jindal RM . Prospective randomized study of individual and group psychotherapy versus controls in recipients of renal transplants. Kidney Int 65 pp 1937-1942 (2004)

[3]Brewster UC, Ciampi MA, Abu-Alfa AK, Perazella MA. Addition of sertralin to othertherapies to reduce dialysis-associated hypotension. Nephrology (Carlton) $8 \mathrm{pp}$ 296-301. (2003)

[4] Raison CL, Capuron L and Miller AH. Cytokines sing the blues: Inflammation and the pathogenesis of depression. Trends Immunol 27(1) pp 24 -31.(2006)

[5] Stenvinkel $P$ and Alvestrand An Inflammation in end-stage renal disease: Sources, consequences, and therapy. Semin Dial 15: 329-337. (2002)

[6]Elvira D, Murni AW Hubungan lamanya durasi hemodialisa dengan derajat depresi pasien dengan penyakit ginjal kronik, KOPAPDI 2012

[7]Zalai D, Szeifert L and Novak M. Psychological distress and depres-sion in patients with chronic kidney disease. Semin Dial 25pp 428-438. (2012)

[8]Halen NV, Cukor D, Constantiner M,Kimmel P. Depression and mortal-ity in end-stage renal disease. Curr Psychiatry Rep 14: 36-44. (2012)

[9]Taylor D, Paton C and Kapur S (eds) Use of psychotropic drugs in special patient groups: Renal Impairment. In: The South London and Maudsley

NHS Foundation Trust Oxleas NHS Foundation Trust Prescribing Guidelines in Psychiatry, 11th Edition. Chichester: Wiley-Blackwell, pp.462-xxx.

[10]Kimmel PL Psychosocial factors in adult end-stage renal dis-ease patients treated with hemodialysis: Correlates and outcomes. Am J of Kidney

Diseases 35: S132-140. (2010) 